\title{
Composite Comprising $\beta$-Sn and Amorphous Mn Phases Formed by Phase Separation during Electrodeposition
}

\author{
M. Saitou \\ University of the Ryukyus, Department of Mechanical Systems Engineering, 1 Senbaru Nishihara-cho \\ Okinawa, 903-0213, Japan. \\ *E-mail: saitou@,tec.u-ryukyu.ac.jp
}

doi: $10.20964 / 2019.02 .21$

Received: 1 November 2018 / Accepted: 29 November 2018 / Published: 5 January 2019

$\mathrm{Sn}-\mathrm{Mn}$ thin films electrodeposited in aqueous solutions having $\mathrm{Mn} / \mathrm{Sn}$ charged molar ratios between 0.05 and 3.5 within a temperature range from 273 to $323 \mathrm{~K}$ were investigated using energy dispersive X-ray spectroscopy (EDX) and X-ray diffraction (XRD). A Mn/Sn critical charged molar ratio at which the Mn contents in the Sn-Mn thin films appreciably changed was observed. The $\mathrm{Mn} / \mathrm{Sn}$ critical charged molar ratio shifted to a larger value with an increase in the deposition temperature. The EDX and XRD analyses demonstrated that the electrodeposited $\mathrm{Sn}-\mathrm{Mn}$ thin films comprised $\beta-\mathrm{Sn}$ and amorphous $\mathrm{Mn}$ phases, and the $\beta$-Sn phase and the amorphous Mn phase formed by the phase separation at the $\mathrm{Mn} / \mathrm{Sn}$ critical charged molar ratio. In addition, the $\mathrm{Sn}-\mathrm{Mn}$ thin films did not include any intermetallic compounds. The Sn-Mn thin films were concluded to be composites comprising the $\beta$-Sn and amorphous $\mathrm{Mn}$ phases. The phase separation and the $\mathrm{Mn} / \mathrm{Sn}$ critical charged molar ratio were explained by a free energy model.

Keywords: Critical charged molar ratio; $\beta$-Sn: Amorphous Mn; Phase separation; Composite; Free energy model

\section{FULL TEXT}

(C) 2019 The Authors. Published by ESG (www.electrochemsci.org). This article is an open access article distributed under the terms and conditions of the Creative Commons Attribution license (http://creativecommons.org/licenses/by/4.0/). 